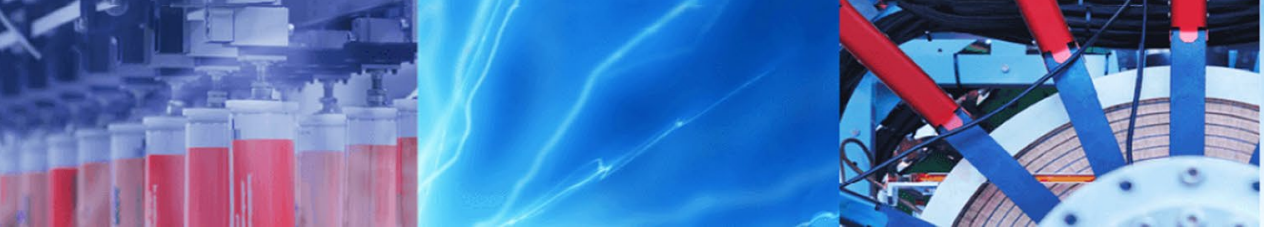

Research Article

\title{
Design optimization of S-shaped compressor transition duct using particle swarm optimization algorithm
}

\author{
Manish Sharma $^{1}$ D $\cdot$ Beena D. Baloni ${ }^{1}$ D
}

Received: 23 July 2019 / Accepted: 6 January 2020 / Published online: 16 January 2020

(c) Springer Nature Switzerland AG 2020

\begin{abstract}
A high-bypass turbofan engine transfers air from low- to the high-pressure compressor through an S-shaped transition duct. Minimization of the total pressure loss and maximization of uniform flow are key factors to ensure the maximum performance of the S-shaped transition duct. The conventional design approach is time-consuming and does not guarantee an optimal solution. Hence, the present article is based on the application of optimization for the S-shaped compressor transition duct. The optimization is carried out on the basis of shape parameters to minimize objectives namely pressure loss coefficient and non-uniformity with the reduction of length of the S-shaped transition duct. The 2-D axisymmetric approach of computational fluid dynamics is used as a design tool for performance evaluation with optimization techniques. The simulation model is validated with the available experimental results of the literature. The correlation between the response and independent variables is established with the help of the second-order polynomial response surface methodology. Further, individual optimization is carried out for single-objective consideration using particle swarm optimization and gray wolf optimization algorithms. As the results of single-objective optimization depict the conflicts between both objectives, later optimization using multi-objective particle swarm optimization and multi-objective gray wolf optimization algorithms is carried out. The performance metrics are obtained and compared. The 'TOPSIS' method is applied to get best solution out of multiple solutions. The optimized duct reduced pressure loss coefficient and non-uniformity index by $28.14 \%$ and $43.33 \%$ with a reduction of $6.37 \%$ of length compared to baseline S-shaped duct.
\end{abstract}

Keywords S-shaped compressor transition duct · Total pressure loss $\cdot$ Non-uniformity index · Pareto-optimal front

\section{Introduction}

Increasing demand for high fuel efficiency and low noise level in commercial aircraft engines propelled to the design of the high-bypass turbofan engines. A twinspool arrangement is the most preferable for adequate bypass ratio and high-pressure ratio turbofan engine [1]. This high-bypass ratio engines are deployed with a larger radial offset and disk bore diameter [2]. An S-shaped transition duct is used to connect the low- and high-pressure turbomachines which have a larger radial offset. In compressor twin-spool arrangement, the inner wall of the $\mathrm{S}$-shaped transition duct is made of convex followed by concave, whereas the outer wall consists of concave followed by convex curvature. As soon as flow approaches to the outer wall of the first bend, its pressure gets higher than the inner wall and consequently across the first bend, a pressure gradient is observed. However, this occurrence is altered within the second bend [3-5]. The S-shaped compressor transition duct is referred to as an S-shaped duct in the subsequent sections of the manuscript. Due to the curvature of the $\mathrm{S}$-shaped duct, the streamwise and radial

Manish Sharma, sharma.manish726@gmail.com | 'Department of Mechanical Engineering, Sardar Vallabhbhai National Institute of Technology, Surat 395007, India. 
direction encounter a pressure gradient and the presence of this pressure gradient significantly modifies the boundary layer development within the S-shaped duct. This is the reason why a vast majority of researchers [6-14] have given paramount importance to the influence of wall curvature on the performance of the S-shaped duct in their studies. Space and weight optimization in the aviation industry dictate that the transition duct must be as shorter as possible without the occurrence of flow separation.

Duenas et al. [15] investigated the effect of reducing the length on the S-shaped duct performance while keeping unchanged inlet duct height $\left(h_{\text {in }}\right)$ and inlet to outlet mean radius difference $(\Delta R)$. Since the performance of the downstream high compressor totally depends on the quality of supplied air, a shorter S-shaped duct is subjected by higher pressure loss due to its curvature and eventually distorts the air quality that ultimately deteriorates the performance of the S-shaped duct. Optimization allows the researcher to obtain a better S-shaped duct design with minimum space requirement along with maximum flow uniformity as well as minimum pressure loss. Even though a number of researches have shown their interest to increase the performance of the S-shaped duct using various optimization techniques, this area of research, particularly for the S-shaped duct, is still needed to be more explored. The computational fluid dynamics (CFD) can be implemented as a design tool for performance evaluation with a combination of various optimization techniques [16]. Many researchers have reported that applying the response surface methodology (RSM) altogether with the design of experiments (DOE) may be a decisive and sturdy method for CFD-based optimization techniques [17-20]. Wallin and Eriksson [17] applied RSM together with DOE to the baseline S-shaped duct containing eight struts for minimizing the total pressure loss and achieved a $24 \%$ reduction of the total pressure loss. Reduction of the total pressure loss by suppressing the peak deceleration in the strut-hub corner region could be achieved through an optimized non-axisymmetric end wall profile that is developed using the RSM approach [18, 19]. Lu et al. [20] exercised the combination of RSM and genetic algorithm (GA) to optimize the S-shaped duct and found a reduction of $36.9 \%$ in total pressure loss with higher uniformity at the outlet.

The single- and multi-objective variants of PSO are reported by many researchers, especially in the thermalrelated problems. Coello and Lechuga [21] presented a proposal first time to make enable PSO to deal with the multi-objective problem. Patel and Rao [22] applied multiobjective particle swarm optimization (MOPSO) algorithm to the shell and tube heat exchanger, and Hojjati et al. [23] implemented MOPSO for the optimal operation of two reservoirs constructed on Ozan River catchment in order to maximize income from power generation and flood control capacity. Alrasheed [24] implemented modified versions of MOPSO to improve its convergence rate and validated its performance through benchmark functions. Peng et al. [25] developed an improved version of PSO to optimize the structural dimensions of the pin-fin heat exchanger and found the optimum weight and overall cost under certain constraints. Alagirusamy et al. [26] applied PSO to find out unknown boundary heat flux for conduction, convection, and coupled conduction-radiation problems. None of the work has been reported by researchers yet to optimize the S-shaped duct using a PSO algorithm. The PSO algorithm allows individual populations to benefit from their past experiences that ultimately contribute to the faster convergence rate than other evolutionary algorithms [27-34]. Many times, computational time taken by PSO for the same number of function evaluations is quite less than other heuristic algorithms [25, 35].

This present work incorporates the design optimization of the S-shaped duct. The total pressure loss coefficient and non-uniformity index at the outlet of the S-shaped duct are selected as responses or objectives function. The MOPSO algorithm has been implemented and for the sake of performance superiority, MOPSO is compared with the multi-objective gray wolf optimization (MOGWO) algorithm. The application of the 'TOPSIS' method is used to obtain an optimal design out of multiple designs of the S-shaped duct.

\section{Numerical simulation}

In order to use CFD as a design tool for performance evaluation with optimization techniques, numerical simulation is carried out for the S-shaped duct. Gambit and Fluent software are used for the entire simulation work.

\subsection{Problem definition}

The prime objective of an S-shaped duct is to supply highquality (maximum uniformity) compressed air with the occurrence of the minimum pressure loss to the downstream high-pressure compressor. The shorter S-shaped duct causes higher pressure loss due to its steep curvature and finally distorts air quality. Hence, total pressure loss and non-uniformity of the flow are directly related to the slope (radial offset) and curvature of the S-shaped duct. An $S$-shaped duct design space is usually defined by the four main geometrical parameters like mean radius ratio $\left(\bar{R}_{r}\right)$, an area ratio $\left(\bar{A}_{r}\right)$, radial offset or slope $(\bar{\gamma})$, and plane of inflection $(\bar{S})$ [36]. Since an S-shaped duct acts as a transition component between low- and high-pressure compressor, inlet dimensions such as inlet hub radius $\left(R_{\mathrm{hi}}\right)$, inlet shroud 
radius $\left(R_{\mathrm{si}}\right)$, and inlet height $\left(h_{\text {inlet }}=R_{\mathrm{si}}-R_{\mathrm{hi}}\right.$ ) are fixed by the existing upstream low-pressure compressor. Complete expression of these geometrical parameters is given below and also shown in Fig. 1 as well.

$\bar{R}_{r}=\frac{R_{\mathrm{si}}+R_{\mathrm{hi}}}{R_{\mathrm{so}}+R_{\mathrm{ho}}}$

$\bar{A}_{r}=\frac{R_{\mathrm{si}}^{2}-R_{\mathrm{hi}}^{2}}{R_{\mathrm{so}}^{2}-R_{\mathrm{ho}}^{2}}$

$\bar{\gamma}=\frac{\left(\bar{R}_{r}-1\right)\left(R_{\mathrm{SO}}+R_{\mathrm{ho}}\right)}{2 L}$

$\bar{S}=\frac{X}{L}$

The S-shaped duct is designed as per the design methodology described by Yurko and Bondarenko [36]. $R_{\mathrm{SO}}$ and $R_{\text {ho }}$ are known as outlet shroud and hub radius, respectively, and can be calculated by solving Eqs. (1) and (2) simultaneously, whereas after selecting proper slope or radial offset, the length can be obtained from Eq. (3). Hub and shroud contours of the S-shaped duct are drawn by using third order parametric Bezier curve [36]; therefore, only four points are just sufficient to define the complete shape of the Bezier curve. Furthermore, both wall shape can be expressed in terms of the cubic curve using Cartesian coordinates $(x, y)$ and a parameter ' $t$ ' and represented by Eqs. (5) and (6). In these equations, ' $t$ ' is the dimensionless length in the axial direction of the Bezier curve and its value should be $0 \leq t \leq 1$.

In the present optimization work, as per existing literature, $\bar{R}_{r}, \bar{\gamma}$ and $\bar{S}$ are selected as the independent variable (design variables), whereas the coefficient of total pressure loss $(\omega)$ and non-uniformity index $\left(S_{\text {io }}\right)$ is selected as the responses which are shown by Eqs. (7) and (8), respectively [37]. The total stagnation pressure loss $\left(P_{\text {oin }}-P_{\text {oout }}\right)$ is nondimensionalized by the dynamic head $\left(0.5 \rho U^{2}\right)$ of the flow and represented by $\omega$, whereas $S_{\text {io }}$ is the ratio of the average velocity in the $y$-direction $\left(U_{y \text { avg }}\right)$ to inlet velocity. To avoid a severe radius change in order to acquire a short length and higher pressure gradients that eventually might provoke the flow separation, Britchford [38] proposed a suitable limit for the hub and shroud pressure rise coefficient for ensuing separation free flow provided that the static pressure rise coefficient on the hub $\left(C_{P_{1}}\right)$ and shroud $\left(C_{P_{2}}\right)$ is less than one $\left(\Delta C_{\text {phub/shroud }} \leq 1\right)$.

The present optimum design of the S-shaped duct is obtained with the imposition of static pressure rise coefficient on the hub and shroud as the constraints. To obtain the objective function and specified constraints, almost 117 numerical simulations have been carried out by altering all three variables by keeping area ratio unity for all cases. To obtain the 117 sets of numerical simulations, the ranges of independent variables are to select and are chosen as per available literature [18, 20, 39] and shown into Eqs. (9), (10), and (11), respectively.

$$
\begin{aligned}
& x(t)=(1-t)^{3} x_{0}+3 t(1-t)^{2} x_{1}+3 t^{2}(1-t) x_{2}+t^{3} x_{3} \\
& y(t)=(1-t)^{3} y_{0}+3 t(1-t)^{2} y_{1}+3 t^{2}(1-t) y_{2}+t^{3} y_{3} \\
& \omega=\left(P_{\text {oin }}-P_{\text {0out }}\right) /\left(0.5 \rho U^{2}\right) \\
& S_{\text {io }}=\left(\sum \sqrt{\left(U_{y}^{2}+U_{z}^{2}\right)}\right) /\left(n U_{\text {avg }}\right)
\end{aligned}
$$

Fig. 1 2-D S-shaped duct geometry

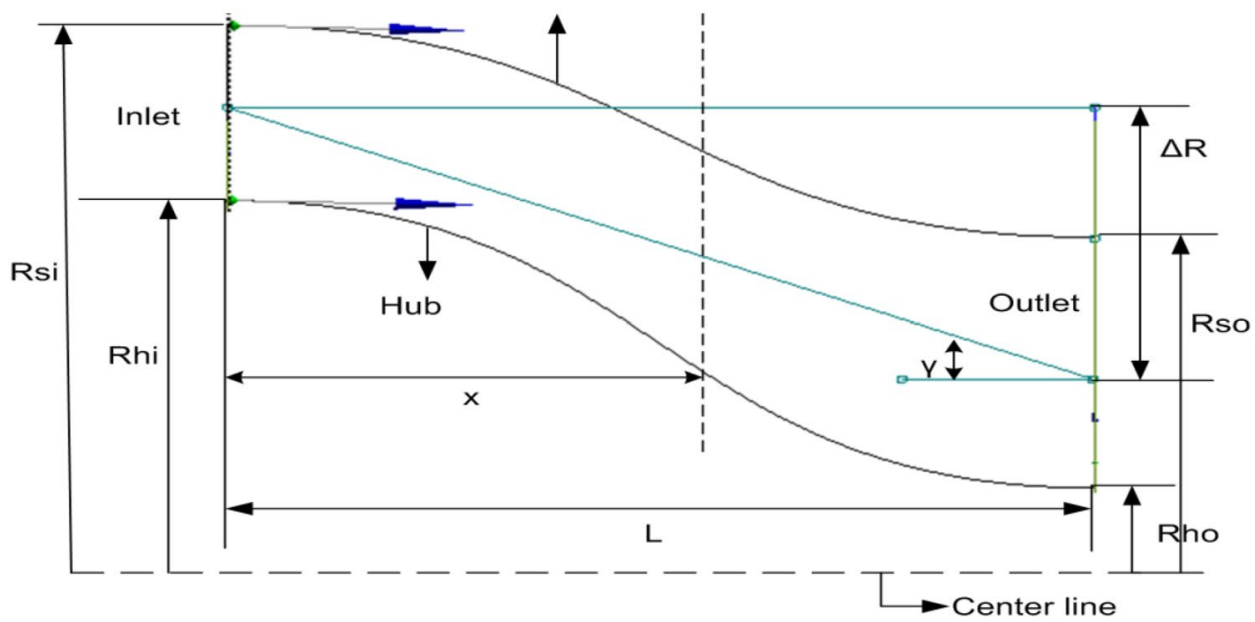

SN Applied Sciences A SPRINGER NATURE journa 
$0.1 \leq \frac{\Delta R}{L}$ or $\leq 0.56$

$1.111 \leq \bar{R}_{r} \leq 1.4287$

$0.4 \leq \bar{S} \leq 0.6$

\subsection{Geometry creation, meshing, and case formation}

With the assumption of uniform flow without swirl at all circumferential direction of the S-shaped duct inlet, a 3-D $\mathrm{S}$-shaped duct can be represented well by the approach of 2-D axisymmetric. This will reduce complexity as well as computational time for convergence of the fluid domain $[2,15,19,38,40,41]$. Modeling and meshing of the 2-D axisymmetric $\mathrm{S}$-shaped duct are accomplished by using 'GAMBIT' software. To obtain an optimum grid size, a grid convergence study is performed for four different grid sizes. Figure 2 represents the variation of the static pressure coefficient along the hub length of the S-shaped duct. The results depict the overlapping of grid $C$ and $D$ throughout the axial length. Therefore, the structured quadrilateral mesh consists of $360 * 180$ grids has been chosen as an optimum mesh size. Even though the detailed study of flow separation and secondary flows within the S-shaped duct is not the scope of the present study, huge mesh elements adjacent to the walls have been deliberately kept in order to accommodate wall nature during the simulation. Comprehensive numerical analysis for all cases of $\mathrm{S}$-shaped duct is performed by using a commercially available CFD code 'Fluent 16.2.'

A cell-centered finite volume approach is implemented to solve the 2-D steady compressible Reynolds-averaged Navier-Stokes equations. All equations are discretized using a second-order upwind scheme, whereas pressure and velocity coupling are confirmed by pressure velocity

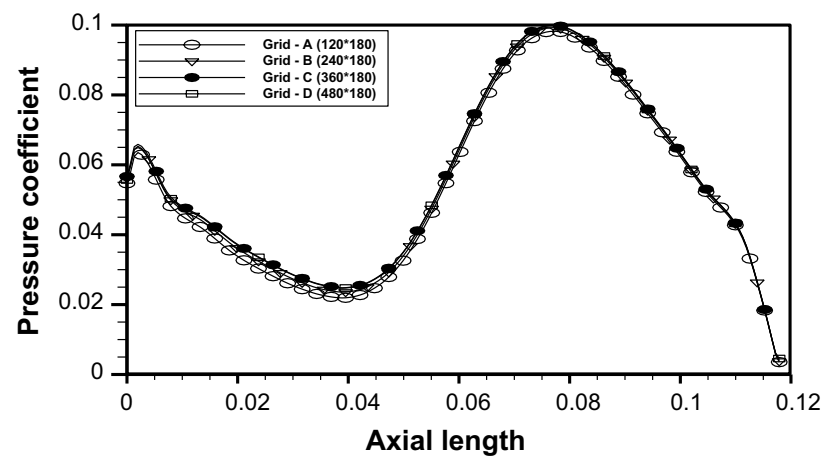

Fig. 2 Grid convergence study correlation using the SIMPLE algorithm. The mass flow rate of $1 \mathrm{~kg} / \mathrm{s}$ is selected as an inlet boundary condition, and outlet pressure of $294,000 \mathrm{~Pa}$ is set as an outlet boundary condition. These conditions were prearranged by the existing upstream low-pressure compressor. Furthermore, hub and shroud walls are specified with no-slip boundary conditions. Flow within the $\mathrm{S}$-shaped duct is turbulent and will significantly be affected by the boundary layers developed along transition duct walls. Hence, to resolve the viscous sub-layer, the SST $k-\omega$ turbulence model with default model constants is selected for all 117 sets of simulation. The convergence criteria for all governing equations are set to $10^{-04}$. The total pressure loss coefficient and non-uniformity index for all the cases are calculated by using Eqs. (7) and (8), respectively, and shown in Table 1 of "Appendix 1".

\subsection{Numerical method validation}

A comparison of the performance of the above proposed numerical model is done with the existing experimental results of the literature [3]. The experimental S-shaped duct was designed with an area ratio of unity. S-shaped duct had inlet height $\left(h_{\text {in }}\right)$ of $71.1 \mathrm{~mm}$ and non-dimensional length $\left(\frac{L}{h_{\text {in }}}\right)$ of 3.4. The radius of curvature of the meanline at the inlet and outlet was $181.3 \mathrm{~mm}$ and $229.65 \mathrm{~mm}$, respectively. As the boundary conditions, the inlet is set at the uniform axial velocity of $28.3 \mathrm{~m} / \mathrm{s}$ and the outlet is set at zero static pressure. Streamwise velocity at the inlet and outlet of the S-shaped duct is non-dimensionalized with the mass-weighted streamwise mean velocity at the inlet. The static pressure coefficient is defined by Eq. (12) where $\tilde{p}_{\text {in }}$ and $\tilde{p}_{\text {in }}$ are the mass-weighted average static and total pressure at inlet, respectively, and $p$ represents the static pressure at a particular location along the S-shaped duct walls.

$C_{p}=\frac{p-\tilde{p}_{\text {in }}}{\tilde{p}_{\text {in }}-\tilde{p}_{\text {in }}}$

Figure 3 is an illustration of a comparison of predicted and existing experimental results [3]. Figure 3a shows the streamwise velocity distribution in the radial direction at the S-shaped duct inlet and outlet. Notably, flow within the S-shaped duct is always subjected by the pressure gradient due to its curvature. The response of the developed boundary layer to this pressure gradient is shown in Fig. 3a, and it could be understood that excluding small discrepancies near to both walls, predicted simulation and experimental results matched quite well. However, similar discrepancies were also reported by the Milanvoic et al. and Immonen $[40,42]$ because of the improper handling of the wall curvature by the turbulence model. Duenas 
Table 1 Independent design variables and values of total pressure loss and nonuniformity index after CFD simulation

\begin{tabular}{|c|c|c|c|c|c|}
\hline S. no. & $\begin{array}{l}\text { Radial offset } \\
(\Delta r / L)\end{array}$ & Radius ratio & $\begin{array}{l}\text { Inflection } \\
\text { plane }\end{array}$ & Total pressure loss & Non-uniformity index \\
\hline 1 & 0.1 & 1.4287 & 0.4 & 0.055146131 & 0.00724232 \\
\hline 2 & 0.16 & 1.4287 & 0.4 & 0.04679094 & 0.01890005 \\
\hline 3 & 0.24 & 1.4287 & 0.4 & 0.044434525 & 0.045518642 \\
\hline 4 & 0.3 & 1.4287 & 0.4 & 0.04668008 & 0.072761018 \\
\hline 5 & 0.38 & 1.4287 & 0.4 & 0.054916074 & 0.115305438 \\
\hline 6 & 0.5 & 1.4287 & 0.4 & 0.079250005 & 0.19372041 \\
\hline 7 & 0.56 & 1.4287 & 0.4 & 0.09301174 & 0.256209467 \\
\hline 8 & 0.1 & 1.33 & 0.4 & 0.050891954 & 0.008351815 \\
\hline 9 & 0.2 & 1.33 & 0.4 & 0.041771158 & 0.036087716 \\
\hline 10 & 0.32 & 1.33 & 0.4 & 0.047139568 & 0.092526019 \\
\hline 11 & 0.4 & 1.33 & 0.4 & 0.059418228 & 0.139557531 \\
\hline 12 & 0.46 & 1.33 & 0.4 & 0.071989877 & 0.185244806 \\
\hline 13 & 0.1 & 1.25 & 0.4 & 0.046063677 & 0.01019097 \\
\hline 14 & 0.16 & 1.25 & 0.4 & 0.040401444 & 0.0290175 \\
\hline 15 & 0.24 & 1.25 & 0.4 & 0.03902277 & 0.060733607 \\
\hline 16 & 0.32 & 1.25 & 0.4 & 0.046020542 & 0.107253439 \\
\hline 17 & 0.36 & 1.25 & 0.4 & 0.051505022 & 0.134675047 \\
\hline 18 & 0.1 & 1.176 & 0.4 & 0.040030103 & 0.012576777 \\
\hline 19 & 0.14 & 1.176 & 0.4 & 0.034027577 & 0.03503498 \\
\hline 20 & 0.22 & 1.176 & 0.4 & 0.034817148 & 0.06401614 \\
\hline 21 & 0.1 & 1.111 & 0.4 & 0.032531999 & 0.022431024 \\
\hline 22 & 0.14 & 1.111 & 0.4 & 0.028582898 & 0.037669353 \\
\hline 23 & 0.18 & 1.111 & 0.4 & 0.028801494 & 0.060584506 \\
\hline 24 & 0.1 & 1.4287 & 0.5 & 0.054904404 & 0.010047121 \\
\hline 25 & 0.12 & 1.4287 & 0.5 & 0.050388496 & 0.01449795 \\
\hline 26 & 0.14 & 1.4287 & 0.5 & 0.047256472 & 0.019754701 \\
\hline 27 & 0.16 & 1.4287 & 0.5 & 0.045098022 & 0.025547193 \\
\hline 28 & 0.18 & 1.4287 & 0.5 & 0.043848755 & 0.03320071 \\
\hline 29 & 0.2 & 1.4287 & 0.5 & 0.043002296 & 0.042100371 \\
\hline 30 & 0.22 & 1.4287 & 0.5 & 0.042391103 & 0.052286466 \\
\hline 31 & 0.24 & 1.4287 & 0.5 & 0.041698223 & 0.063715306 \\
\hline 32 & 0.26 & 1.4287 & 0.5 & 0.040862183 & 0.075013337 \\
\hline 33 & 0.28 & 1.4287 & 0.5 & 0.040790707 & 0.087596423 \\
\hline 34 & 0.3 & 1.4287 & 0.5 & 0.041077653 & 0.101006742 \\
\hline 35 & 0.32 & 1.4287 & 0.5 & 0.041698223 & 0.114729293 \\
\hline 36 & 0.34 & 1.4287 & 0.5 & 0.042652834 & 0.129081609 \\
\hline 37 & 0.36 & 1.4287 & 0.5 & 0.04386355 & 0.144606146 \\
\hline 38 & 0.38 & 1.4287 & 0.5 & 0.045488952 & 0.161242674 \\
\hline 39 & 0.4 & 1.4287 & 0.5 & 0.047618853 & 0.178542504 \\
\hline 40 & 0.42 & 1.4287 & 0.5 & 0.050905499 & 0.19494154 \\
\hline 41 & 0.44 & 1.4287 & 0.5 & 0.053529898 & 0.216196352 \\
\hline 42 & 0.46 & 1.4287 & 0.5 & 0.056737982 & 0.239679239 \\
\hline 43 & 0.48 & 1.4287 & 0.5 & 0.060611857 & 0.266413003 \\
\hline 44 & 0.5 & 1.4287 & 0.5 & 0.06512964 & 0.298981269 \\
\hline 45 & 0.52 & 1.4287 & 0.5 & 0.071213852 & 0.332710793 \\
\hline 46 & 0.54 & 1.4287 & 0.5 & 0.081964843 & 0.369262729 \\
\hline 47 & 0.56 & 1.4287 & 0.5 & 0.084542563 & 0.392056495 \\
\hline 48 & 0.1 & 1.33 & 0.5 & 0.050319313 & 0.011482723 \\
\hline 49 & 0.12 & 1.33 & 0.5 & 0.046314156 & 0.016629962 \\
\hline 50 & 0.14 & 1.33 & 0.5 & 0.043540554 & 0.022361872 \\
\hline
\end{tabular}


Table 1 (continued)

\begin{tabular}{|c|c|c|c|c|c|}
\hline S. no. & $\begin{array}{l}\text { Radial offset } \\
(\Delta r / L)\end{array}$ & Radius ratio & $\begin{array}{l}\text { Inflection } \\
\text { plane }\end{array}$ & Total pressure loss & Non-uniformity index \\
\hline 51 & 0.16 & 1.33 & 0.5 & 0.041841801 & 0.030108783 \\
\hline 52 & 0.18 & 1.33 & 0.5 & 0.040713188 & 0.039407003 \\
\hline 53 & 0.2 & 1.33 & 0.5 & 0.039646466 & 0.050193001 \\
\hline 54 & 0.22 & 1.33 & 0.5 & 0.038395324 & 0.061289378 \\
\hline 55 & 0.24 & 1.33 & 0.5 & 0.037833518 & 0.073041729 \\
\hline 56 & 0.26 & 1.33 & 0.5 & 0.037779338 & 0.08614931 \\
\hline 57 & 0.28 & 1.33 & 0.5 & 0.038135051 & 0.099336923 \\
\hline 58 & 0.3 & 1.33 & 0.5 & 0.038845226 & 0.113499181 \\
\hline 59 & 0.32 & 1.33 & 0.5 & 0.03989757 & 0.128502866 \\
\hline 60 & 0.34 & 1.33 & 0.5 & 0.041197266 & 0.144815195 \\
\hline 61 & 0.36 & 1.33 & 0.5 & 0.042805789 & 0.162834268 \\
\hline 62 & 0.38 & 1.33 & 0.5 & 0.044731473 & 0.182024767 \\
\hline 63 & 0.4 & 1.33 & 0.5 & 0.046782188 & 0.20313575 \\
\hline 64 & 0.42 & 1.33 & 0.5 & 0.050878617 & 0.221817835 \\
\hline 65 & 0.44 & 1.33 & 0.5 & 0.054162346 & 0.246167174 \\
\hline 66 & 0.46 & 1.33 & 0.5 & 0.057615283 & 0.276452718 \\
\hline 67 & 0.1 & 1.25 & 0.5 & 0.045252227 & 0.013670548 \\
\hline 68 & 0.12 & 1.25 & 0.5 & 0.041690721 & 0.019378026 \\
\hline 69 & 0.14 & 1.25 & 0.5 & 0.039532688 & 0.027273171 \\
\hline 70 & 0.16 & 1.25 & 0.5 & 0.037892699 & 0.037313217 \\
\hline 71 & 0.18 & 1.25 & 0.5 & 0.036616551 & 0.048891322 \\
\hline 72 & 0.2 & 1.25 & 0.5 & 0.034991149 & 0.059845343 \\
\hline 73 & 0.22 & 1.25 & 0.5 & 0.034467061 & 0.072488601 \\
\hline 74 & 0.24 & 1.25 & 0.5 & 0.034498527 & 0.085266435 \\
\hline 75 & 0.26 & 1.25 & 0.5 & 0.034950514 & 0.09916879 \\
\hline 76 & 0.28 & 1.25 & 0.5 & 0.035744877 & 0.114231587 \\
\hline 77 & 0.3 & 1.25 & 0.5 & 0.036792844 & 0.130649777 \\
\hline 78 & 0.32 & 1.25 & 0.5 & 0.038128174 & 0.148161591 \\
\hline 79 & 0.34 & 1.25 & 0.5 & 0.0398486 & 0.167160776 \\
\hline 80 & 0.36 & 1.25 & 0.5 & 0.041828255 & 0.187415164 \\
\hline 81 & 0.1 & 1.176 & 0.5 & 0.038811468 & 0.016960994 \\
\hline 82 & 0.12 & 1.176 & 0.5 & 0.036035782 & 0.026163716 \\
\hline 83 & 0.14 & 1.176 & 0.5 & 0.033960894 & 0.03757796 \\
\hline 84 & 0.16 & 1.176 & 0.5 & 0.031713672 & 0.04884316 \\
\hline 85 & 0.18 & 1.176 & 0.5 & 0.030695921 & 0.061444271 \\
\hline 86 & 0.2 & 1.176 & 0.5 & 0.030358545 & 0.074607187 \\
\hline 87 & 0.22 & 1.176 & 0.5 & 0.03055797 & 0.088744233 \\
\hline 88 & 0.24 & 1.176 & 0.5 & 0.031028294 & 0.104867784 \\
\hline 89 & 0.26 & 1.176 & 0.5 & 0.03189205 & 0.121748256 \\
\hline 90 & 0.1 & 1.111 & 0.5 & 0.030978282 & 0.027453868 \\
\hline 91 & 0.12 & 1.111 & 0.5 & 0.028438488 & 0.04200433 \\
\hline 92 & 0.14 & 1.111 & 0.5 & 0.0262617 & 0.052815223 \\
\hline 93 & 0.16 & 1.111 & 0.5 & 0.025559234 & 0.067154667 \\
\hline 94 & 0.18 & 1.111 & 0.5 & 0.02541524 & 0.083154964 \\
\hline 95 & 0.1 & 1.4287 & 0.6 & 0.055116957 & 0.015304618 \\
\hline 96 & 0.16 & 1.4287 & 0.6 & 0.044710218 & 0.039237634 \\
\hline 97 & 0.24 & 1.4287 & 0.6 & 0.040096161 & 0.093286118 \\
\hline 98 & 0.3 & 1.4287 & 0.6 & 0.038047321 & 0.149180776 \\
\hline 99 & 0.38 & 1.4287 & 0.6 & 0.039873189 & 0.243404119 \\
\hline 100 & 0.5 & 1.4287 & 0.6 & 0.067225991 & 0.441505555 \\
\hline
\end{tabular}


Table 1 (continued)

\begin{tabular}{llllll}
\hline S. no. & $\begin{array}{l}\text { Radial offset } \\
(\Delta r / L)\end{array}$ & Radius ratio & $\begin{array}{l}\text { Inflection } \\
\text { plane }\end{array}$ & Total pressure loss & Non-uniformity index \\
\hline 101 & 0.56 & 1.4287 & 0.6 & 0.071802956 & 0.539306748 \\
102 & 0.1 & 1.33 & 0.6 & 0.050364532 & 0.017480345 \\
103 & 0.2 & 1.33 & 0.6 & 0.038322806 & 0.073425045 \\
104 & 0.32 & 1.33 & 0.6 & 0.03565548 & 0.189983363 \\
105 & 0.4 & 1.33 & 0.6 & 0.043230477 & 0.303645159 \\
106 & 0.46 & 1.33 & 0.6 & 0.057742814 & 0.410455568 \\
107 & 0.1 & 1.25 & 0.6 & 0.045015502 & 0.020638679 \\
108 & 0.16 & 1.25 & 0.6 & 0.036830562 & 0.054802913 \\
109 & 0.24 & 1.25 & 0.6 & 0.031696585 & 0.126307346 \\
110 & 0.32 & 1.25 & 0.6 & 0.033430972 & 0.215706653 \\
111 & 0.36 & 1.25 & 0.6 & 0.036309183 & 0.274625326 \\
112 & 0.1 & 1.176 & 0.6 & 0.038337393 & 0.025793165 \\
113 & 0.14 & 1.176 & 0.6 & 0.030839914 & 0.071737627 \\
114 & 0.22 & 1.176 & 0.6 & 0.027665797 & 0.129374563 \\
115 & 0.1 & 1.111 & 0.6 & 0.030192463 & 0.039187167 \\
116 & 0.14 & 1.111 & 0.6 & 0.0236 & 0.096658605 \\
117 & 0.18 & 1.111 & 0.6 & 0.023144679 & 0.117276496 \\
\hline
\end{tabular}

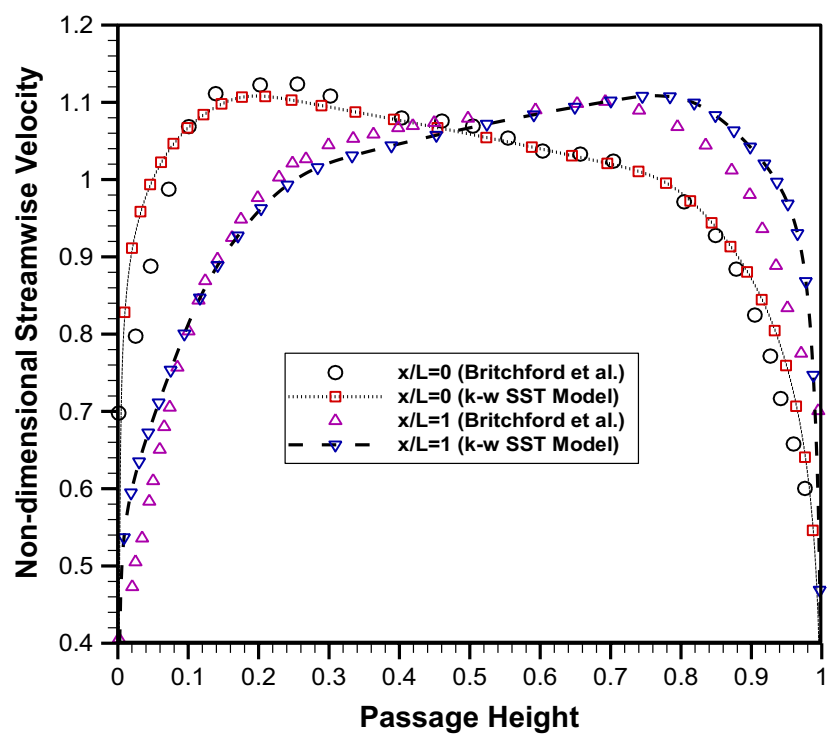

(a) S-shaped annular duct geometry

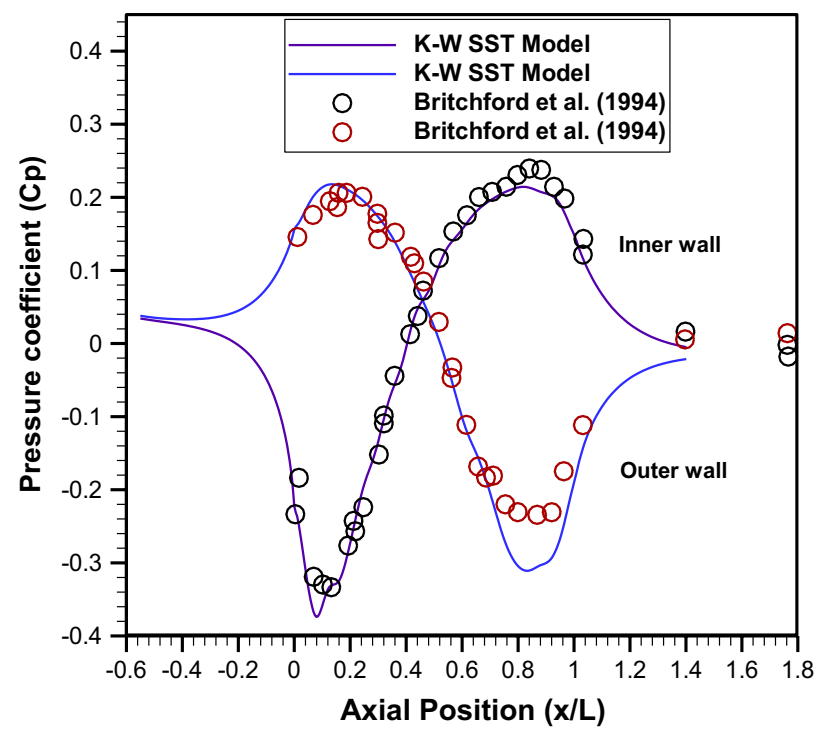

(b) Axial variation of static pressure coefficient

Fig. 3 Comparison of predicted results with existing literature

et al. [15] had also commented that it might be difficult the accurate prediction of flow under the highly curved wall surface by Boussinesq eddy-viscosity turbulence models. Figure $3 \mathrm{~b}$ exhibits the static pressure coefficient distribution on the hub and shroud is accurately predicted by the $k-\omega$ SST turbulence model except the region near to the valley, where it is over-predicted. Even though there is a minor deviation between predicted and experimental results along the S-shaped duct wall, the proposed turbulence model is quite sufficient to capture the flow field in the S-shaped duct for optimization.

\section{Optimization}

In order to carry out S-shaped duct optimization, total pressure loss coefficient $(\omega)$ and non-uniformity index $\left(S_{i o}\right)$ obtained from the numerical simulations need to be 
modeled as the objective functions in terms of design variables. Hence, the regression model development and its analysis are carried out in the following subsection. After obtaining the regression model, a concise description of the PSO algorithm and the formation of the multi-objective functions are reported. As at least two performance metrics must be evaluated hence, spacing metric and hypervolume indicator are elaborated to validate the performance of the MOPSO algorithm. At last, to select one best alternative from the Pareto solutions obtained from the MOPSO, the 'TOPSIS' method is described.

\subsection{Formulation of the regression model}

Regression analysis is considered as a worthy tool in statistical modeling to reckon the relationship between the dependent and independent variables, and it uses several techniques to model and analyze the response which is influenced by a number of variables. As one cannot obtain objective function directly in terms of specified design parameters, a direct relation between them can be established with the regression model.

A second-degree polynomial regression model based on response surface methodology (RSM) is used to establish the correlation between the response and independent variables. This regression model is widely applied to the aerodynamic configuration design by many researchers [20,43-45]. The output of a second-order polynomial RSM is expressed by Eq. (13) where $\beta, N$, and $x$ denote the regression analysis coefficients, the number of design variables, and a set of design variables, respectively.

$f(x)=\beta_{0}+\sum_{j=1}^{N} \beta_{j} x_{j}+\sum_{j=1}^{N} \beta_{j j} x_{j}^{2}+\sum \sum_{i \neq j}^{N} \beta_{i j} x_{i} x_{j}$

Based on the numerical simulations, total pressure loss and non-uniformity index (shown in Table 1 of "Appendix 1") have been calculated and are expressed in terms of the second-order RSM model by using MINITAB 18 statistical software. The regression equations of total pressure loss coefficient and non-uniformity index in terms of independent variables are shown by Eqs. (14) and (15), respectively. To check the individual parameter's significance on both objective function, ANOVA tables are obtained and are represented by Tables 2 and 3 of "Appendix 1", respectively. The appropriateness of a regression model is expressed by $F$-value and $P$-value. For better appropriateness, an independent variable of higher $F$-value is desirable, whereas, at the same time, its $P$-value must be
Table 2 ANOVA for total pressure loss model through regression analysis

\begin{tabular}{|c|c|c|c|c|c|}
\hline Source & DF & $\begin{array}{l}\text { Adjusted } \\
\text { sum of } \\
\text { square }\end{array}$ & $\begin{array}{l}\text { Adjusted } \\
\text { mean of the } \\
\text { square }\end{array}$ & $F$-value & $P$-value \\
\hline Regression & 9 & 0.018310 & 0.002034 & 981.83 & 0.000 \\
\hline$\Delta R / L$ & 1 & 0.000028 & 0.000028 & 13.56 & 0.000 \\
\hline $\bar{R}_{r}$ & 1 & 0.000169 & 0.000169 & 81.54 & 0.000 \\
\hline $\bar{S}$ & 1 & 0.000053 & 0.000053 & 25.60 & 0.000 \\
\hline$(\Delta R / L)^{2}$ & 1 & 0.004678 & 0.004678 & 2257.76 & 0.000 \\
\hline$\left(\bar{R}_{r}\right)^{2}$ & 1 & 0.000116 & 0.000116 & 56.07 & 0.000 \\
\hline$(\bar{S})^{2}$ & 1 & 0.000055 & 0.000055 & 26.52 & 0.000 \\
\hline $\begin{array}{c}(\Delta R / L) \\
*\left(\bar{R}_{r}\right)\end{array}$ & 1 & 0.000167 & 0.000167 & 80.39 & 0.000 \\
\hline$(\Delta R / L) *(S)$ & 1 & 0.000327 & 0.000327 & 157.92 & 0.000 \\
\hline$\left(\bar{R}_{r}\right) *(S)$ & 1 & 0.000013 & 0.000013 & 6.09 & 0.015 \\
\hline Error & 107 & 0.000222 & 0.000002 & & \\
\hline Total & 116 & 0.018531 & & & \\
\hline
\end{tabular}

Table 3 ANOVA for non-uniformity index model through regression analysis

\begin{tabular}{lrllrl}
\hline Source & DF & $\begin{array}{l}\text { Adjusted } \\
\text { sum of } \\
\text { square }\end{array}$ & $\begin{array}{l}\text { Adjusted } \\
\text { mean of the } \\
\text { square }\end{array}$ & F-value & $P$-value \\
\hline Regression & 9 & 1.22653 & 0.136282 & 2332.94 & 0.000 \\
$\Delta R / L$ & 1 & 0.00018 & 0.000185 & 3.16 & 0.078 \\
$\bar{R}_{r}$ & 1 & 0.00107 & 0.001070 & 18.31 & 0.000 \\
$\bar{S}$ & 1 & 0.00068 & 0.000680 & 11.63 & 0.001 \\
$(\Delta R / L)^{2}$ & 1 & 0.03671 & 0.036711 & 628.43 & 0.000 \\
$\left(\bar{R}_{r}\right)^{2}$ & 1 & 0.00172 & 0.001722 & 29.47 & 0.000 \\
$(\bar{S})^{2}$ & 1 & 0.00255 & 0.002551 & 43.67 & 0.000 \\
$(\Delta R / L)^{*}\left(\bar{R}_{r}\right)$ & 1 & 0.00478 & 0.004777 & 81.77 & 0.000 \\
$(\Delta R / L)^{*}(S)$ & 1 & 0.05670 & 0.056703 & 970.67 & 0.000 \\
$\left(\bar{R}_{r}\right)^{*}(S)$ & 1 & 0.00093 & 0.000927 & 15.88 & 0.000 \\
Error & 107 & 0.00625 & 0.000058 & & \\
Total & 116 & 1.23278 & & & \\
\hline
\end{tabular}

lower. Tables 2 and 3 depict that all variables and their combined interactions significantly affect the objectives. Furthermore, the model confidence level is represented by $R^{2}$ which is also known as the coefficient of determination. It shows the impact of approximation of a proposed regression version and it is far considered as a higher impact of approximation of a proposed version when $R^{2}$ value is nearer to 1.0. Table 4 depicts that the proposed models fit well to the present case and describe perfectly to the problem. 
Table 4 Model summary for total pressure loss coefficient and nonuniformity index $\left(S_{i 0}\right)$

\begin{tabular}{lllll}
\hline & $S$ & $R$-square (\%) & $\begin{array}{l}R \text {-square } \\
\text { (adj.) }(\%)\end{array}$ & $\begin{array}{l}R \text {-square } \\
\text { (pred.) } \\
(\%)\end{array}$ \\
\hline $\begin{array}{l}\text { Total pres- } \\
\text { sure loss } \\
\text { coefficient } \\
(\omega)\end{array}$ & 0.0014395 & 98.80 & 98.70 & 98.42 \\
$\begin{array}{c}\text { Non-uni- } \\
\text { formity } \\
\text { index }\left(S_{\text {io }}\right)\end{array}$ & 0.0076431 & 99.49 & 99.45 & 99.31 \\
\hline
\end{tabular}

Total pressure loss $(\omega)$

$$
\begin{aligned}
= & {\left[-0.1926+\{0.0939 \times \Delta R / L\}+\left\{0.3826 \times \bar{R}_{r}\right\}\right.} \\
& -\{0.1940 \times \bar{S}\}+\left\{0.5105 \times(\Delta R / L)^{2}\right\} \\
& -\left\{0.1249 \times\left(\bar{R}_{r}\right)^{2}\right\}+\left\{0.1428 \times(\bar{S})^{2}\right\} \\
& -\left\{0.1785 \times(\Delta R / L) \times\left(\bar{R}_{r}\right)\right\}-\{0.2246 \\
& \left.\times(\Delta R / L) \times(\bar{S})\}+\left\{0.0540 \times\left(\bar{R}_{r}\right) \times(\bar{S})\right\}\right]
\end{aligned}
$$

Non-Uniformity Index $\left(\mathrm{S}_{\mathrm{io}}\right)$

$$
\begin{aligned}
= & {\left[-0.837-\{0.241 \times \Delta R / L\}-\left\{0.963 \times \bar{R}_{r}\right\}\right.} \\
& -\{0.694 \times \bar{S}\}+\left\{0.1 .4300 \times(\Delta R / L)^{2}\right\} \\
& +\left\{0.4806 \times\left(\bar{R}_{r}\right)^{2}\right\}+\left\{0.973 \times(\bar{S})^{2}\right\} \\
& -\left\{0.956 \times(\Delta R / L) \times\left(\bar{R}_{r}\right)\right\} \\
& +\{2.9570 \times(\Delta R / L) \times(\bar{S})\} \\
& \left.-\left\{0.463 \times\left(\bar{R}_{r}\right) \times(\bar{S})\right\}\right]
\end{aligned}
$$

Since the present article's aim is to find out the optimum design of the S-shaped duct under the constraints, the static pressure rise coefficient is considered as a constraint. The regression Eqs. (16) and (17) depict the $C_{P 1}$ and $C_{P 2}$, respectively, in terms of independent variables. Optimization algorithm searches the optimum design for $\omega$ and $S_{\text {io }}$ as well only if the optimum design well satisfies the given constraints.

$$
\begin{aligned}
C_{P 1}= & \max \left\{\max \left(\left.C_{P}\right|_{\text {Hub }}\right)-\min \left(\left.C_{P}\right|_{\text {Hub }}\right)\right\} \\
C_{P 2}= & \max \left\{\max \left(\left.C_{P}\right|_{\text {Shroud }}\right)-\min \left(\left.C_{P}\right|_{\text {Shroud }}\right)\right\} \\
C_{P 1}= & 3.096+\{4.257 \times \Delta R / L\}-\left\{4.142 \times \bar{R}_{r}\right\} \\
& -\{1.647 \times \bar{S}\}-\left\{1.327 \times(\Delta R / L)^{2}\right\}+\left\{1.452 \times\left(\bar{R}_{r}\right)^{2}\right\} \\
& \left.+\left\{1.899 \times(\bar{S})^{2}\right\}-\{0.515\} \times(\Delta R / L) \times\left(\bar{R}_{r}\right)\right\} \\
& \left.+\{0.014 \times(\Delta R / L) \times(\bar{S})\}-\{0.123\} \times\left(\bar{R}_{r}\right) \times(\bar{S})\right\}
\end{aligned}
$$

$$
\begin{aligned}
C_{P 2}= & 4.460+\{14.393 \times \Delta R / L\}-\left\{4.69 \times \bar{R}_{r}\right\} \\
& -\{8.14 \times \bar{S}\}-\left\{8.116 \times(\Delta R / L)^{2}\right\}+\left\{1.185 \times\left(\bar{R}_{r}\right)^{2}\right\} \\
& \left.+\left\{3.795 \times(\bar{S})^{2}\right\}-\{7.222\} \times(\Delta R / L) \times\left(\bar{R}_{r}\right)\right\} \\
& \left.+\{8.437 \times(\Delta R / L) \times(\bar{S})\}-\{4.228\} \times\left(\bar{R}_{r}\right) \times(\bar{S})\right\}
\end{aligned}
$$

\subsection{Particle swarm optimization algorithm}

PSO algorithm is a probabilistic optimization technique and developed by Kennedy and Eberhart [46]. In swarm intelligence, PSO is one of the popularized evolutionary techniques which is inspired by the group behavior of animal, for example, school of fish and flocks of birds. Like other swarm intelligence, PSO also shows general computation traits including initialization with a population of the random solutions as well as finding out the optimum by keeping update the generations. PSO works for a potential solution and the population in the potential solution known as a swarm and each individual in the swarm is considered as a particle. Each and every particle into the swarm finds their best solution depending on their own experience and other particles into the same swarm as well. This personal best value is marked as 'pBest'; meanwhile, there is another best value that is achieved in global space by the particle, and it is the best value as well as corresponding best locations so far in the entire population. This value is marked as 'gBest.' In addition to it, the velocity of each particle at each step continuously updates toward its 'pBest' and 'gBest' locations, and the updated velocity and location of the particle during each iteration are expressed by Eqs. (18) and (19), respectively.

$V_{i+1}=w V_{i}+C_{1} r_{1}\left(\right.$ pBest $\left._{i}-X_{i}\right)+C_{2} r_{2}\left(\right.$ gBest $\left._{i}-X_{i}\right)$

$X_{i+1}=X_{i}+V_{i+1}$

Equation (18) calculates the new velocity $V_{i+1}$ the individual particle by using the previous velocity, best location ('pBest') and obtained global best location ('gBest') into the entire population as well and at the same time, individual particle's location $\left(X_{i}\right)$ in the hyperspace is updated by the Eq. (19). In the Eq. (18), $r_{1}$ and $r_{2}$ are the independently generated random numbers within the range of $[0,1]$, whereas $C_{1}$ and $C_{2}$ are the acceleration constants to represent the weight of stochastic acceleration term that pulls each particle toward 'pBest' and 'gBest' positions. ' $C{ }_{1}$ ' is the cognitive parameter that 
indicates the confidence has a particle itself. ' $C_{2}$ '. is the social parameter and depicts the confidence that has a particle into the swarm. In general, tuning of these parameters alters tension into the system. Low values of them allow particles to roam far from target regions before being tugged back, while high value results in the abrupt movement toward, or past through target regions [47].

Apart from it, the particle's velocities on each dimension are confined to maximum velocity $\left(V_{\max }\right.$ which is a parameter specified by the user. If the sum of accelerations would cause the velocity on that dimension to exceed $V_{\max }$, then the velocity on that dimension is limited to $V_{\text {max }}$. Similarly, if the maximum value of $X_{i+1}$ is exceeding the upper limit of the corresponding design space, then it has to restrict up to the upper limit of the design space and if the minimum value of $X_{i+1}$ is exceeding the lower limit of the corresponding design space, then it has to restrict up to the lower limit of the design space. In Eq. (18), ' $w$ ' is the inertia weight and its value must be between 0.4 and 1.4 [48]. It decides the convergence behavior of the PSO algorithm by controlling the exploration abilities of the swarm. High inertia weight permits a wide velocity update which ultimately allows to globally explore the design space, whereas low inertia weight targets the velocity updates in the confined region of the design space. An optimum value of ' $w$ ' enhances the performance of the PSO algorithm in many applications.

\subsection{Formation of the multi-objective optimization function}

Coello and Lechugo [21] proposed a methodology to deal with the PSO with the multi-objective environment and the present work replicates the same methodology; however, tuning of algorithm-specific parameters has been carried out. It is well evident that the design of the S-shaped duct involves multiple inputs and requires the simultaneous optimization of multiple responses. Accordingly, it is essential to formulate the multi-objective optimization problems (MOOPs) and also establish the Pareto-efficient set of solutions. As per the literature, MOOPs can either be solved using a priori approach or posteriori approach. In order to obtain a set of distinct solutions, one has to assign the weight to each objective and required to run the algorithm independently for each set of weights in case of priori approach, whereas posteriori approach neither requires to assign any weight to the objectives nor needs to run multiple time. Set of Pareto-efficient solutions are obtained into a single run in case of posteriori approach and as per the importance of the objectives, the decision-maker can select any one solution from the set. This superiority of the posteriori approach over the priori approach motivated the researchers to adopt the posteriori approach.

In the present work, a posteriori approach-based nature-inspired multi-objective version of PSO is implemented to solve the MOOP of the S-shaped duct. The main aim of the MOOP is to find out a vector of design variables even as performing optimization (minimizing or maximizing) of several objectives at the same time, under a given set of constraints. For the present work, two such objectives namely minimization of the total pressure loss and the non-uniformity index (secondary flow at the outlet) at the outlet of the S-shaped duct are chosen concurrently for multi-objective optimization. The objectives are shown by Eqs. (20) and (21), respectively. As the constraints, static pressure rise coefficient on the hub $\left(C_{P 1}\right)$ and shroud $\left(C_{P_{2}}\right)$ with limits is shown by Eqs. (22) and (23), respectively.

$\omega=$ Minimize $\omega\left(\gamma, \bar{R}_{r}, \bar{S}\right)$

$S_{i 0}=$ Minimize $S_{i 0}\left(\gamma, \bar{R}_{r}, \bar{S}\right)$

Subject to

$C_{P 1} \leq 1$

$C_{P 2} \leq 1$

where

$\gamma_{\min } \leq \gamma \leq \gamma_{\max }$

$\bar{R}_{r \min } \leq \bar{R}_{r} \leq \bar{R}_{r \max }$

$\bar{S}_{\min } \leq \bar{S} \leq \bar{S}_{\max }$

In order to demonstrate the effectiveness of the MOPSO algorithm, the results of MOPSO are compared with the MOGWO algorithm. Mirjalili et al. [49] proposed the multiobjective version of the gray wolf optimization (GWO) algorithm for the first time. Authors integrated a fixed size external archive to save and retrieve the Pareto-optimal solutions. The same multi-objective version of the GWO algorithm is implemented for the present work. Application of the MOGWO algorithm can be found in various fields like heat and power dispatch with cogeneration systems [50], the design of the Stirling engine [51], and the design of heat exchanger [52] and many more. Therefore, considering the effectiveness of the MOGWO algorithm in solving the multi-objective optimization problems of various fields, the present work depicts the application of the MOGWO algorithm in the field of the S-shaped duct, 
and the results are compared with the results of MOPSO algorithm.

\subsection{Performance measure}

Even though a number of multi-objective evolutionary algorithms (MOEAs) are available, the effort is made in the continuing pursuit of more efficient and effective designs to search for Pareto-optimal solutions for a given problem. Neither of the MOEAs gives a guarantee to figure out the optimal trade-off, however, attempts to find out a better approximation. According to Zitzler et al. [53], objective space with uniform distribution and approximated nondominated solutions with the maximum extent are most desirable. Although existing literature provides numerous performance metrics calculator to compare the MOEAs, no single metrics alone can faithfully measure MOEA performance. Every metric can provide some specific, but incomplete, quantifications of performance and can only be used effectively under specified conditions. To overcome such shortcomings and ensure the fair evaluation of MOEAs, it is supposed to calculate at least two performance metrics together. In the present article to compare the algorithms, spacing metric (SP) proposed by Schott [54] and hypervolume indicator proposed by Zitzler et al. [53] are employed.

\subsubsection{Spacing metric $(S)$}

In order to measure how evenly the non-dominated solutions are distributed in the approximated Pareto front, the spacing metric [54] is widely used and expressed by Eq. (24). It calculates the relative distance between the consecutive solutions of non-dominated Pareto front.

$S=\sqrt{\frac{1}{n-1} \sum_{i=1}^{n}\left(\bar{d}-d_{i}\right)^{2}}$

where $\bar{d}$ is the average of all $d_{i}, \mathrm{n}$ is the number of the Pareto-optimal solution in the approximated Pareto front, and $d_{i}$ is calculated as follows.

$d_{i}=\min _{k \in n, k \neq i}\left\{\sum_{m=1}^{M}\left|f_{m}^{i}-f_{m}^{k}\right|\right\}$

In the above mathematical notation, $i$ and $k$ denote the number of solutions. It represents the minimum value of the sum of the absolute difference in objective function values between the ith and consecutive solutions of non-dominated Pareto front. Its value is small when the obtained solutions are evenly spaced and very close to each other. Therefore, an algorithm finding a set of non-dominated solutions having a smaller spacing $(S)$ is better.

\subsubsection{Hypervolume indicator $(H)$}

It indicates the volume covered (area in the case of biobjective optimization problem) of the search space which is dominated by the Pareto front with respect to a given reference point. An algorithm with a higher value of hypervolume is most desirable and shows the superiority of the obtained Pareto front. A Pareto front is considered as the superior only if (1) it contains high-quality solutions (superior solutions in terms of objective function values) (2) pertaining the diversity among the solutions (the solutions in a Pareto front must be uniformly distributed as much as possible) and (3) pertinence (a Pareto front must contain as many numbers of solutions as possible and ultimately give maximum possible choices to the decisionmaker) [55]. A hypervolume compared the Pareto fronts on the basis of all three aforementioned performance criteria simultaneously. A Pareto front containing $n$ solutions, hypervolume $v_{i}$ is calculated between a reference point $W$ and $i$ th solution as the diagonal corner of the hypercube. Similarly, the union of all such hypercube is calculated and its hypervolume is given by the Eq. (25).

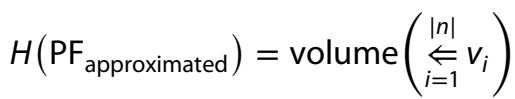

\subsection{Multi-criteria decision making using the TOPSIS method}

Multi-criteria decision making (MCDM) offers to choose the best alternative from multiple Pareto-optimal solutions (usually conflicting nature) provided by an evolutionary algorithm. Multiple Pareto-optimal solutions obtained from the evolutionary algorithms (in the present case-MOPSO) are treated as alternatives, and the objective function is set up as the selection criteria. There are numerous multi-criteria techniques like MAXMIN, MAXMAX, SAW, AHP, TOPSIS, PROMETHEE, SMART, and ELECTRE are most frequently used. Hwang and Yoon [56] introduced a multicriteria decision making method named as 'the technique for an order of preference by similarity to ideal solution (TOPSIS)' and exhibited how it plays a significant role to decide the preference and ranking in various engineering fields. This method points out an alternative solution which is closest to the ideal solution and farthest to the negative ideal solution in a multi-dimensional computing space. Therefore, in the present work, the 'TOPSIS' method is applied to pick up the best solution out-off the multiple 
Pareto-optimal solutions provided by MOPSO. In the present work, the complete procedure for implementation of the 'TOPSIS' method has been followed as per Hwang and Yoon [56].

\section{Results and discussion}

The individual optimization carried out for single-objective consideration using PSO and GWO algorithms. Since single-objective consideration depicts the conflict between both objectives, multi-objective optimization using MOPSO and MOGWO algorithms is performed. Further, to check the superiority, the performance metrics for both algorithms are presented. The best alternative given by the 'TOPSIS' is also reported and based on the best alternative, a comparison between the performance of the baseline and optimized S-shaped duct is done.

\subsection{Comparison of results obtained by single-objective consideration}

At first, the optimization of the S-shaped duct is accomplished by considering all two objective functions individually (as a single-objective problem) for two different approaches PSO and GWO. For targeting the above, a population size of 10 and the number of iterations of 50 were considered during the implementation of MATLAB code for both of the algorithms. Table 5 reveals the comparison of optimized design parameters and responses of an S-shaped duct obtained using PSO and GWO for singleobjective consideration. It can be understood from Table 5 that design corresponding to minimum total pressure loss leads to a higher non-uniformity index. Likewise, design corresponding to minimum non-uniformity index leads to higher total pressure loss. However, PSO showed slightly better-optimized value than GWO algorithm; for example, during individual consideration of minimum total pressure loss and non-uniformity index, PSO gives the lower value of pressure loss $(\omega)$ and non-uniformity index $\left(S_{i 0}\right)$ than the GWO algorithm.

Table 5 reveals that $\omega$ and $S_{i 0}$ are mutually conflicting in nature; hence, design parameters setting which gives the minimum value of $\omega(0.021298)$ may increase $S_{i 0}$ $(0.174300)$, whereas the minimum value of $S_{i 0}(0.0048954)$ may lead to a maximum value of $\omega(0.0509718)$. A slight modification of any parameter that can improve one objective will lead to the inferior value of another objective. Therefore, it is essential to make a proper trade-off between $\omega$ and $S_{i 0}$ to find out the optimum design of the S-shaped duct. MOPSO and MOGWO algorithms are implemented to simultaneously optimize $\omega$ and $S_{i 0}$ and multiple optimal solutions are obtained.

\subsection{Comparison of MOPSO and MOGWO}

In this section, results obtained from the MOPSO are compared to MOGWO. In order to obtain the Pareto front and make a comparison of algorithms, performance following input parameters is chosen.

\begin{tabular}{|c|c|}
\hline$W($ inertia weight $)=0.5$ & Alpha (inflation rate) $=0.1$ \\
\hline Wdamp $=0.99$ & $\begin{array}{l}\text { Beta (Leader selection pres- } \\
\text { sure) }=4\end{array}$ \\
\hline $\begin{array}{l}\text { C1 (Personal learning coeffi- } \\
\text { cient })=1\end{array}$ & $\begin{array}{l}\text { Gamma (Deletion selection pres- } \\
\text { sure) }=2\end{array}$ \\
\hline $\begin{array}{l}\text { C2 (Global learning coeffi- } \\
\text { cient) }=2\end{array}$ & $\mu$ (Mutation rate $)=0.1$ \\
\hline $\begin{array}{l}\text { nGrid (Number of grid per } \\
\text { dimension) }=10\end{array}$ & Population size $=50$ \\
\hline Iteration number $=100$ & \\
\hline
\end{tabular}

Table 6 Statistical result of metric of spacing (SS)

\begin{tabular}{lll}
\hline SS & MOPSO & MOGWO \\
\hline Maximum & 0.00266734 & 0.00350583 \\
Minimum & 0.00143733 & 0.00212046 \\
Average & 0.00204735 & 0.00266915 \\
SD & 0.00048765 & 0.00059030
\end{tabular}

Table 5 Optimal output variables for single-objective consideration

\begin{tabular}{llllll}
\hline & PSO & & \multicolumn{2}{l}{ GWO } \\
\cline { 2 - 3 } & $\begin{array}{l}\text { Minimum total pressure loss } \\
(\omega) \text { consideration }\end{array}$ & $\begin{array}{l}\text { Minimum non-uniformity index } \\
\left(S_{i 0}\right) \text { consideration }\end{array}$ & $\begin{array}{l}\text { Minimum total pressure loss } \\
(\omega) \text { consideration }\end{array}$ & $\begin{array}{l}\text { Minimum non-uniformity } \\
\text { index }\left(S_{i 0}\right) \text { consideration }\end{array}$ \\
\hline$Y(\Delta R / L)$ & 0.23423 & 0.10000 & 0.234 & 0.1 \\
$\bar{R}_{r}$ & 1.1110 & 1.35520 & 1.111 & 1.355 \\
$\bar{S}$ & 0.60000 & 0.52712 & 0.599 & 0.527 \\
$\omega$ & 0.021298 & 0.0509718 & 0.0213330 & 0.05096 \\
$S_{i 0}$ & 0.174300 & 0.0048954 & 0.173450 & 0.0049159 \\
\hline
\end{tabular}


Table 7 Statistical result of the hypervolume indicator

\begin{tabular}{lll}
\hline $\mathrm{H}$ & MOPSO & MOGWO \\
\hline Maximum & 0.97302578 & 0.97291334 \\
Minimum & 0.97278300 & 0.96968080 \\
Average & 0.97294200 & 0.97163814 \\
SD & 0.00013652 & 0.00119757 \\
\hline
\end{tabular}

To make an effective comparison, input parameters were kept identical for both of the algorithms, and posteriori version of both algorithms is employed. Like the MOPSO, MOGWO also intends proper tuning of the algorithm-specific parameters which are kept the same as MOPSO. Spacing metric $(S)$ and hypervolume indicator are well known as a performance metric and allow to make quantitatively and qualitatively comparison of MOPSO and MOGWO. Both algorithms are independently run 5 times on the test problems, and note that each algorithm solves 5000 function evaluations per run.

Obtained statistical results for both of the algorithms are illustrated in Tables 6 and 7. Table 6 depicts the statistical results of the algorithm for the metrics of spacing (S). Since the metrics of spacing may be a better choice to benchmark whether the solutions are evenly spaced as well as very close to each other. The results of Table 6 show that for the present problem, solutions obtained from the MOPSO are not only evenly spaced but also very close to each other. Furthermore, MOPSO is able to outperform for all the statistical results and shows lower values of average, maximum, minimum, and standard deviation than MOGWO. It proves that MOPSO has better coverage than MOGWO.

Similarly, Table 7 illustrates the statistical results of the hypervolume indicator. As already discussed, an algorithm with a higher value of the hypervolume is most desirable and a higher value of the hypervolume means that obtained Pareto front has superior quality. Table 8 depicts that volume covered by the MOPSO with respect to a given reference point is higher than the MOGWO. Also, MOPSO gives the higher value of the hypervolume indicator including its average, maximum, minimum, and standard deviation. Finally, it can be concluded that the Pareto

Table 8 Statistical result of the CPU time required by each algorithm

\begin{tabular}{lcc}
\hline CPU time (s) & MOPSO & MOGWO \\
\hline Best & 3.467867 & 17.30425 \\
Worst & 5.108755 & 19.43425 \\
Average & 4.435046 & 17.72651 \\
SD & 0.384305 & 0.459800 \\
\hline
\end{tabular}

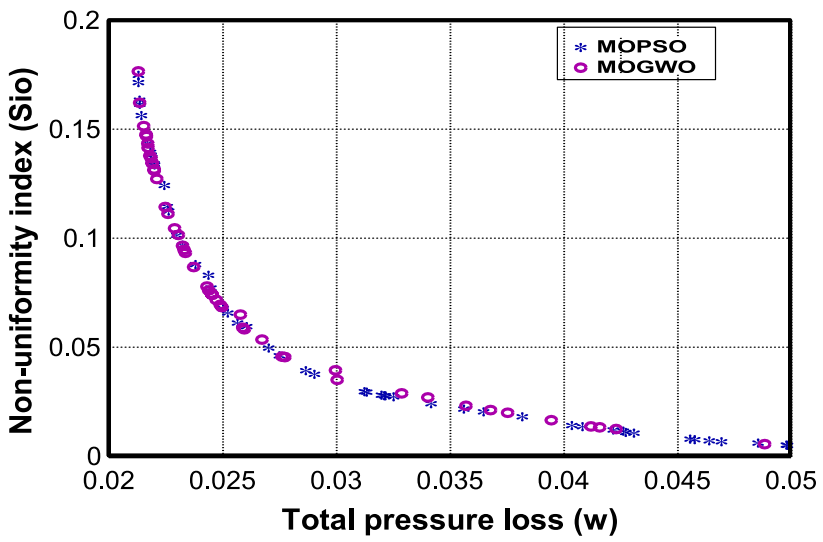

Fig. 4 Pareto fronts obtained by MOPSO and MOGWO algorithms

front obtained from the MOPSO algorithm has superior quality than MOGWO. Table 8 shows the statistical result of the computational time taken by each algorithm. It reveals that the MOPSO algorithm takes less time to solve the present problem than MOGWO and it is almost five times faster than the MOGWO algorithm.

Figure 4 shows the Pareto front obtained from MOPSO and MOGWO algorithms. It contains 50 Pareto-optimal solutions for both of the algorithms. "Appendix 2" shows the Pareto-optimal set of solutions obtained from the MOPSO. It contains fifty optimal combinations of input design parameters like $\bar{R}_{r}, \bar{\gamma}$, and $\bar{S}$ along with the corresponding values of pressure loss and non-uniformity index. Now the designer has the choice to select any one solution out of the 50 solutions provided by the MOPSO based on his order of preference given to $\omega$ and $S_{i 0}$.

\subsection{Result of optimization}

The baseline S-shaped duct was designed as proposed by the Britchford [38]. The baseline S-shaped duct was designed with an area ratio of unity, whereas inlet height $\left(h_{\text {inlet }}\right)$ was fixed due to the existence of the upstream low-pressure compressor and it was $0.008271 \mathrm{~m}$. The non-dimensional length $\left(L / h_{\text {inlet }}\right)$ was 3.4 , and inlet hub radius to height ratio $\left(R_{\mathrm{hi}} / h_{\text {inlet }}\right)$ was 4.25 . The radial offset or slope $(\gamma)$ and mean radius ratio were 0.28 and 1.25 , respectively. From Fig. 4, it could be understood that the MOPSO algorithm provides 50 optimal solutions; hence, to select one best alternative out of 50 Pareto-optimal solutions, one of the multi-criteria decision making (MCDM) method named 'TOPSIS' is applied. Since the importance of both objectives is unknown, initially equal importance has been given to both the objectives during the implementation of the 'TOPSIS.'Even though equal importance shows a significant reduction in pressure loss coefficient and non-uniformity index in comparison with baseline duct, 
Table 9 The best choice provided by 'TOPSIS' method corresponding to a different set of weights

\begin{tabular}{|c|c|c|c|c|c|c|c|}
\hline \multirow[t]{3}{*}{ S. no. } & \multirow{2}{*}{\multicolumn{2}{|c|}{$\begin{array}{l}\text { Weights assign to } \\
\text { the criteria }\end{array}$}} & \multicolumn{5}{|c|}{ Best choice provided by TOPSIS method } \\
\hline & & & \multicolumn{3}{|c|}{ Design parameters } & \multicolumn{2}{|c|}{ Criteria/responses } \\
\hline & $w_{1}$ & $w_{2}$ & $\gamma$ & $\bar{R}_{r}$ & $\bar{S}$ & $\omega$ & $S_{i 0}$ \\
\hline 1 & 0.5 & 0.5 & 0.1 & 1.11819 & 0.50067 & 0.03124 & 0.02968 \\
\hline 2 & 0.8 & 0.2 & 0.14906 & 1.111 & 0.51743 & 0.02566 & 0.06116 \\
\hline
\end{tabular}

Table 10 Comparison of design and response parameters between baseline and optimized S-shaped duct

\begin{tabular}{|c|c|c|c|c|c|c|}
\hline & $\begin{array}{l}\text { Radial offset }(\gamma \\
\text { or } \Delta R / L)\end{array}$ & Radius ratio $\left(\bar{R}_{r}\right)$ & $\begin{array}{l}\text { Location of inflec- } \\
\text { tion plane }(\bar{S})\end{array}$ & $\begin{array}{l}\text { Non-dimensional } \\
\text { length }\left(L / h_{\text {inlet }}\right)\end{array}$ & $\begin{array}{l}\text { Total pr. loss coef- } \\
\text { ficient }(\omega)\end{array}$ & $\begin{array}{l}\text { Non- } \\
\text { uniformity } \\
\text { index }\left(S_{i 0}\right)\end{array}$ \\
\hline Initial design & 0.28 & 1.250 & 0.50000 & 3.40 & 0.035709 & 0.107926 \\
\hline Optimized design & 0.14906 & 1.111 & 0.51743 & 3.18 & 0.02566 & 0.06116 \\
\hline$\%$ reduction & & & & 6.37 & 28.14 & 43.33 \\
\hline
\end{tabular}

it does not satisfy the space and weight criteria which are the essential restrictions in the aerospace industry. Hence, in order to satisfy these restrictions, 0.8 and 0.2 weights are given to the total pressure loss coefficient and non-uniformity index, respectively. The value of different weights and their corresponding design parameters and responses are shown in Table 9.

A comparison between the design parameters and responses of the baseline and optimized S-shaped duct are shown in Table 10. In order to obtain the lower values of the pressure loss and non-uniformity than the baseline S-shaped duct, design parameters are needed to be optimized. Table 10 shows that the radius ratio and radial offset of the optimized duct are reduced, whereas the inflection plane (matching point) is slightly shifted toward the downstream. It indicates that a more moderate pressure gradient distribution is achieved despite the reduction in length. During the optimization process, severe change in the curvature of the baseline S-shaped duct is brought lower by reducing the radial offset in such a way that it helps to reduce the pressure loss and non-uniformity at the duct exit by $28.14 \%$ and $43.33 \%$, respectively.
However, decreasing the radius ratio of the optimized $\mathrm{S}$-shaped duct also leads to a high hub-to-tip ratio (HTR) at duct exit as duct height needs to be decreased to maintain the area. The optimized design yields a $6.37 \%$ reduction in the length without flow separation which leads to weight and space reduction of the S-shaped duct for the aerospace application.

\section{Conclusions}

Applications of an S-shaped duct in the aerospace industry open the scope of optimization. Especially, weight and space restriction demands the optimal design of an S-shaped duct. Total pressure loss and non-uniformity at the S-shaped duct outlet have substantial importance to quantify the performance of the S-shaped duct. Hence, an optimal design of the $S$-shaped duct is necessitated for the minimum pressure loss and non-uniformity at the outlet of the S-shaped duct. Such a multi-objective optimization problem has been exercised here using the MOPSO algorithm. Due to the conflicting nature of the objective 
functions, Pareto-optimal solutions were obtained and the performance of MOPSO was compared with the MOGWO algorithm. The following concluding remarks are drawn from the present work.

- Due to conflicting nature of the present objective functions, which generally occur in multi-objective problems, it can be concluded that a slight modification of any parameter that can improve the total pressure loss coefficient causes to the inferior value of non-uniformity index and vice versa.

- The better maximum, minimum, average, and standard deviation value of the spacing metric, hypervolume indicator, and computational time are obtained by the MOPSO than the MOGWO algorithm. This shows the superiority of the MOPSO over the MOGWO algorithm for the present case.

- Since MOPSO provides a wide range of optimal solutions, it enables the designer to choose any particular solution that corresponds to a specific order of importance of the objectives and even in the situations whenever the order of importance of objectives is subjected to frequent changes. Thus to select an optimum design of the S-shaped duct, the proposed procedure may be considered for real production.

- The best alternative suggested by the 'TOPSIS' method reports a reduction of $6.37 \%, 28.14 \%$, and $43.33 \%$ in length, pressure loss coefficient, and non-uniformity index for the optimized S-shaped duct compared to baseline S-shaped duct.

Acknowledegments The authors would like to thank Dr. R. V. Rao, Professor, Mechanical Engineering Department, Sardar Vallabhbhai National Institute of Technology, Surat, for valuable suggestions to improve the quality of this article.

\section{Compliance with ethical standards}

Conflict of interest The authors have no conflict of interest.

\section{Appendix 1}

See Tables 1, 2, and 3.

\section{Appendix 2}

See Table 11.

Table 11 Pareto-optimal solutions obtained using MOPSO algorithm

\begin{tabular}{|c|c|c|c|c|c|}
\hline S. no. & $\gamma$ & $\bar{R}_{r}$ & $\bar{S}$ & $\omega$ & $S_{i 0}$ \\
\hline 1 & 0.10000 & 1.33556 & 0.51112 & 0.04979 & 0.00518 \\
\hline 2 & 0.20632 & 1.11100 & 0.60000 & 0.02170 & 0.14364 \\
\hline 3 & 0.15998 & 1.11100 & 0.51484 & 0.02503 & 0.06777 \\
\hline 4 & 0.21813 & 1.11100 & 0.60000 & 0.02143 & 0.15636 \\
\hline 5 & 0.23169 & 1.11100 & 0.60000 & 0.02130 & 0.17147 \\
\hline 6 & 0.10000 & 1.12571 & 0.49459 & 0.03216 & 0.02779 \\
\hline 7 & 0.10000 & 1.27165 & 0.49962 & 0.04556 & 0.00793 \\
\hline 8 & 0.19739 & 1.11100 & 0.60000 & 0.02199 & 0.13427 \\
\hline 9 & 0.10000 & 1.12389 & 0.49242 & 0.03199 & 0.02807 \\
\hline 10 & 0.16115 & 1.11100 & 0.50399 & 0.02523 & 0.06575 \\
\hline 11 & 0.10000 & 1.15872 & 0.49956 & 0.03561 & 0.02169 \\
\hline 12 & 0.10000 & 1.33597 & 0.52023 & 0.04984 & 0.00506 \\
\hline 13 & 0.10000 & 1.12376 & 0.48437 & 0.03211 & 0.02784 \\
\hline 14 & 0.22451 & 1.11100 & 0.60000 & 0.02135 & 0.16341 \\
\hline 15 & 0.10000 & 1.21222 & 0.48843 & 0.04083 & 0.01362 \\
\hline 16 & 0.10000 & 1.27464 & 0.50578 & 0.04576 & 0.00766 \\
\hline 17 & 0.10000 & 1.11819 & 0.50067 & 0.03124 & 0.02968 \\
\hline 18 & 0.20116 & 1.11100 & 0.60000 & 0.02186 & 0.13819 \\
\hline 19 & 0.10000 & 1.16430 & 0.47764 & 0.03648 & 0.02043 \\
\hline 20 & 0.19678 & 1.11100 & 0.60000 & 0.02201 & 0.13364 \\
\hline 21 & 0.10000 & 1.28337 & 0.50386 & 0.04640 & 0.00713 \\
\hline 22 & 0.12831 & 1.11100 & 0.50490 & 0.02750 & 0.04615 \\
\hline 23 & 0.16072 & 1.11100 & 0.47718 & 0.02606 & 0.05953 \\
\hline 24 & 0.10000 & 1.14467 & 0.49714 & 0.03417 & 0.02416 \\
\hline 25 & 0.18938 & 1.11100 & 0.53610 & 0.02324 & 0.09686 \\
\hline 26 & 0.10000 & 1.24079 & 0.51378 & 0.04309 & 0.01066 \\
\hline 27 & 0.14906 & 1.11100 & 0.51743 & 0.02566 & 0.06116 \\
\hline 28 & 0.10000 & 1.20795 & 0.49700 & 0.04036 & 0.01415 \\
\hline 29 & 0.10000 & 1.23226 & 0.48202 & 0.04262 & 0.01158 \\
\hline 30 & 0.10000 & 1.29104 & 0.50323 & 0.04694 & 0.00672 \\
\hline 31 & 0.20011 & 1.11100 & 0.60000 & 0.02189 & 0.13710 \\
\hline 32 & 0.22281 & 1.11100 & 0.60000 & 0.02136 & 0.16152 \\
\hline 33 & 0.10000 & 1.18613 & 0.52039 & 0.03818 & 0.01816 \\
\hline 34 & 0.18734 & 1.11100 & 0.51664 & 0.02381 & 0.08799 \\
\hline 35 & 0.21527 & 1.11100 & 0.57590 & 0.02183 & 0.13945 \\
\hline 36 & 0.10000 & 1.23010 & 0.52096 & 0.04218 & 0.01210 \\
\hline 37 & 0.11708 & 1.11100 & 0.47953 & 0.02904 & 0.03765 \\
\hline 38 & 0.10000 & 1.31337 & 0.53909 & 0.04855 & 0.00611 \\
\hline 39 & 0.10126 & 1.12965 & 0.48955 & 0.03252 & 0.02733 \\
\hline 40 & 0.23463 & 1.11100 & 0.60000 & 0.02130 & 0.17482 \\
\hline 41 & 0.14099 & 1.11100 & 0.48283 & 0.02703 & 0.04970 \\
\hline 42 & 0.10000 & 1.11504 & 0.47417 & 0.03134 & 0.02946 \\
\hline 43 & 0.18816 & 1.11100 & 0.54987 & 0.02299 & 0.10143 \\
\hline 44 & 0.11690 & 1.11100 & 0.49904 & 0.02866 & 0.03932 \\
\hline 45 & 0.21456 & 1.11100 & 0.54805 & 0.02244 & 0.12426 \\
\hline 46 & 0.10000 & 1.23550 & 0.49803 & 0.04273 & 0.01100 \\
\hline 47 & 0.20318 & 1.11100 & 0.54962 & 0.02257 & 0.11457 \\
\hline 48 & 0.20138 & 1.11100 & 0.54862 & 0.02263 & 0.11250 \\
\hline 49 & 0.15867 & 1.11100 & 0.54971 & 0.02449 & 0.07723 \\
\hline
\end{tabular}


Table 11 (continued)

\begin{tabular}{llllll}
\hline S. no. & $\gamma$ & $\bar{R}_{r}$ & $\bar{S}$ & $\omega$ & $S_{i 0}$ \\
\hline 50 & 0.18982 & 1.11107 & 0.49660 & 0.02438 & 0.08307 \\
\hline
\end{tabular}

\section{References}

1. Saravanamuttoo HIH, Rogers GFC, Cohen H (2001) Gas turbine theory, 5th edn. Pearson Education Ltd., London

2. Kurzke J (2009) Fundamental differences between conventional and geared turbofans. In: Proceeding of ASME Turbo Expo 2009: power for land, sea and air. ASME, Orlando, pp 1-9

3. Britchford KM, Manners AP, McGuirk JJ, Stevens SJ (1994) Measurement and prediction of low in annular S-shaped ducts. Exp Therm Fluid Sci 9:197-205. https://doi.org/10.1016/08941777(94)90112-0

4. Bailey DW (1997) The aerodynamic performance of an annular S-shaped duct. Loughborough University, Loughborough

5. Bailey DW, Britchford KM, Carrote JF, Stevens SJ (1997) Performance assessment of an annular S-shaped duct. J Turbomach 119:149-156. https://doi.org/10.1115/1.2841003

6. Vakili A, Wu J, Liver P, Bhat M (1983) Measurements of compressible secondary flow in a circular S-duct. In: 16th Fluid and plasma dynamics conference. American Institute of Aeronautics and Astronautics, Danvers, pp 1-14

7. Vakili A, Wu J, Hingst W, Towne C (1984) Comparison of experimental and computational compressible flow in a S-duct. In: 22nd Aerospace sciences meeting. American Institute of Aeronautics and Astronautics, Reno, Nevada, pp 1-8

8. Wellborn S, Reichert B, Okiishi T (1992) An experimental investigation of the flow in a diffusing S-duct. In: 28th Joint propulsion conference and exhibit. American Institute of Aeronautics and Astronautics, Nashville, pp 1-12

9. Taylor AMKP, Whitelaw JH, Yianneskis M (1982) Developing flow in S-shaped ducts I-square cross-section duct, NASA Contractor Report-3550

10. Taylor P, Whitelaw JH (1984) Developing flow in S-shaped ducts II- circular cross-section, NASA Contractor Report-3759

11. Vaccaro JC, Elimelech $Y$, Chen $Y$ et al (2013) Experimental and numerical investigation on the flow field within a compact inlet duct. Int J Heat Fluid Flow 44:478-488. https://doi. org/10.1016/j.ijheatfluidflow.2013.08.004

12. Anand RB, Rai L, Singh SN (2003) Effect of the turning angle on the flow and performance characteristics of long S-shaped circular diffusers. Proc Inst Mech Eng Part G J Aerosp Eng 217:29-41. https://doi.org/10.1243/095441003763031815

13. Smith CF, Bruns JE, Harloff GJ, De Bonis JR (1992) Three-dimensional compressible turbulent computations for a diffusing S-duct, NASA Contractor Report-4392

14. Harloff GJ, Smith C, Bruns JE (1992) Three-dimensional compressible turbulent computations for a nondiffusing S-duct, NASA Contractor Report-4391

15. Ortiz Dueñas C, Miller RJ, Hodson HP, Longley JP (2007) Effect of length on compressor Inter-stage duct performance. In: Proceedings of GT2007 ASME Turbo Expo 2007: Power for land, sea and air. ASME, Montreal, pp 319-329

16. Ghisu T, Molinari M, Parks G et al (2007) Axial compressor intermediate duct design and optimisation. In: 48th AIAA/ASME/ ASCE/AHS/ASC structures, structural dynamics, and materials conference. American Institute of Aeronautics and Astronautics, Reston, Virigina, pp 1-14
17. Wallin F, Eriksson L (2006) Response surface-based transition duct shape optimization. In: ASME Turbo Expo 2006: Power for land, sea and air. ASME, Barcelona, pp 1465-1474

18. Naylor EMJ, Dueñas CO, Miller RJ, Hodson HP (2010) Optimization of nonaxisymmetric endwalls in compressor S-shaped ducts. J Turbomach 132:011011. https://doi. org/10.1115/1.3103927

19. Jin D, Liu X, Zhao W, Gui X (2015) Optimization of endwall contouring in axial compressor S-shaped ducts. Chin J Aeronaut 28:1076-1086. https://doi.org/10.1016/j.cja.2015.06.011

20. Lu H, Zheng X, Li Q (2014) A combinatorial optimization design method applied to S-shaped compressor transition duct design. Proc Inst Mech Eng Part G J Aerosp Eng 228:1749-1758. https://doi.org/10.1177/0954410014531922

21. Coello AC, Lechuga MS (2002) MOPSO : a proposal for multiple objective particle swarm (2002). In: Proceedings of the 2002 congress on evolutionary computation. CEC'02 (Cat. No.02TH8600), pp 1051-1056

22. Patel VK, Rao RV (2010) Design optimization of shell-and-tube heat exchanger using particle swarm optimization technique. Appl Therm Eng 30:1417-1425. https://doi.org/10.1016/j.applt hermaleng.2010.03.001

23. Hojjati A, Monadi M, Faridhosseini A, Mohammadi M (2018) Application and comparison of NSGA-II and MOPSO in multi-objective optimization of water resources systems. J Hydrol Hydromech 66:323-329. https://doi.org/10.2478/ johh-2018-0006

24. Alrasheed MRA (2011) A modified particle swarm optimization and its application in thermal management of an electronic cooling system. The University of British Columbia, Vancouver

25. Peng $\mathrm{H}$, Ling $\mathrm{X}, \mathrm{Wu} \mathrm{E}$ (2010) An improved particle swarm algorithm for optimal design of plate-fin heat exchangers. Ind Eng Chem Res 49:6144-6149. https://doi.org/10.1021/ie1002685

26. Alagirusamy R, Talukdar $P$, Udayraj et al (2015) Performance analysis and feasibility study of ant colony optimization, particle swarm optimization and cuckoo search algorithms for inverse heat transfer problems. Int J Heat Mass Transf 89:359378. https://doi.org/10.1016/j.ijheatmasstransfer.2015.05.015

27. Zhang X, Zheng X, Cheng R et al (2018) A competitive mechanism based multi-objective particle swarm optimizer with fast convergence. Inf Sci (NY) 427:63-76. https://doi.org/10.1016/j. ins.2017.10.037

28. Tsai SJ, Sun TY, Liu CC et al (2010) An improved multi-objective particle swarm optimizer for multi-objective problems. Expert Syst Appl 37:5872-5886. https://doi.org/10.1016/j. eswa.2010.02.018

29. Tripathi PK, Bandyopadhyay S, Pal SK (2007) Multi-objective particle swarm optimization with time variant inertia and acceleration coefficients. Inf Sci (NY) 177:5033-5049. https:// doi.org/10.1016/j.ins.2007.06.018

30. Tanweer MR, Al-Dujaili A, Suresh S (2017) Multi-objective self regulating particle swarm optimization algorithm for BMOBench platform. In: 2016 IEEE Symposium Series Computational Intelligence (SSCI 2016). https://doi.org/10.1109/ ssci.2016.7850234

31. Meza J, Espitia H, Montenegro C et al (2017) MOVPSO: vortex multi-objective particle swarm optimization. Appl Soft Comput J 52:1042-1057. https://doi.org/10.1016/j.asoc.2016.09.026

32. Lee KH, Baek SW, Kim KW (2008) Inverse radiation analysis using repulsive particle swarm optimization algorithm. Int J Heat Mass Transf 51:2772-2783. https://doi.org/10.1016/j.ijheatmasstrans fer.2007.09.037

33. Goh CK, Tan KC, Liu DS, Chiam SC (2010) A competitive and cooperative co-evolutionary approach to multi-objective particle swarm optimization algorithm design. Eur J Oper Res 202:42-54. https://doi.org/10.1016/j.ejor.2009.05.005 
34. Cartwright $\mathrm{H}$ (2002) Swarm intelligence. By James Kennedy and Russell C Eberhart with Yuhui Shi. Morgan Kaufmann Publishers: San Francisco, 2001. 43.95. xxvii + 512 pp. ISBN 1-55860-595-9. Chem Educ. https://doi.org/10.1007/s00897020553a

35. Elhossini A, Areibi S, Dony R (2010) Strength pareto particle swarm optimization and hybrid EA-PSO for multi-objective optimization. Evol Comput. https://doi.org/10.1162/ evco.2010.18.1.18105

36. Yurko I, Bondarenko G (2014) A new approach to designing the S-shaped annular duct for industrial centrifugal compressor. Int J Rotat Mach 2014:1-10. https://doi.org/10.1155/2014/925368

37. Gopaliya MK, Chaudhary KK (2010) CFD analysis of performance characteristics of Y-shaped diffuser with combined horizontal and vertical offsets. Aerosp Sci Technol 14:338-347. https://doi. org/10.1016/j.ast.2010.02.008

38. Britchford KM (1998) The aerodynamic behaviour of an annular S-shaped duct. Loughborough University, Loughborough

39. Karakasis MK, Naylor EMJ, Miller RJ, Hodson HP (2010) The effect of an upstream compressor on a non-axisymmetric S-duct. In: Volume 7: turbomachinery, Parts A, B, and C. ASME, Glasgow, pp 477-486

40. Immonen E (2018) Shape optimization of annular S-ducts by CFD and high-order polynomial response surfaces. Eng Comput 35:932-954. https://doi.org/10.1108/EC-08-2017-0327

41. Marn DA (2008) On the aerodynamics of aggressive intermediate turbine ducts for competitive and environmentally friendly jet engines. Graz University of Technology, Graz

42. Milanovic IM, Whiton J, Florea RV et al (2014) RANS simulations for sensitivity analysis of compressor transition duct. In: 50th AIAA/ASME/SAE/ASEE joint propulsion conference. American Institute of Aeronautics and Astronautics, Cleveland, pp 1-9

43. Kim J-H, Kim J-W, Kim K-Y (2011) Axial-flow ventilation fan design through multi-objective optimization to enhance aerodynamic performance. J Fluids Eng 133:101101-1-101101-12. https://doi.org/10.1115/1.4004906

44. Liu X, Zhang W (2010) Two schemes of multi-objective aerodynamic optimization for centrifugal impeller using response surface model and genetic algorithm. In: Volume 7: turbomachinery, Parts A, B, and C. ASME, pp 1041-1053

45. Zhu C, Qin G (2010) Design technology of centrifugal fan impeller based on response surface methodology. In: ASME 2010 3rd Joint US-European fluids engineering summer meeting: Volume 1, Symposia-Parts A, B, and C. ASME, pp 117-125
46. Kennedy J, Eberhart R (1995) Particle swarm optimization. In: Proceedings of ICNN'95-international conference on neural networks. IEEE, Perth, pp 1942-1948

47. Dong Y, Tang J, Xu B, Wang D (2005) An application of swarm optimization to nonlinear programming. Comput Math Appl 49:1655-1668. https://doi.org/10.1016/j.camwa.2005.02.006

48. Monsef H, Naghashzadegan M, Jamali A, Farmani R (2019) Comparison of evolutionary multi objective optimization algorithms in optimum design of water distribution network. Ain Shams Eng J 10:103-111

49. Mirjalili S, Saremi S, Mirjalili SM, Coelho LDS (2016) Multiobjective grey wolf optimizer: a novel algorithm for multi-criterion optimization. Expert Syst Appl 47:106-119. https://doi. org/10.1016/j.eswa.2015.10.039

50. Jayakumar N, Subramanian S, Ganesan S, Elanchezhian EB (2016) Grey wolf optimization for combined heat and power dispatch with cogeneration systems. Int J Electr Power Energy Syst 74:252-264. https://doi.org/10.1016/j.ijepes.2015.07.031

51. Zare SH, Badjian H (2017) Multi-objective optimization of stirling heat engine using gray wolf optimization algorithm. Int J Eng 30:895-903. https://doi.org/10.5829/ije.2017.30.06c.10

52. Majumder M, Barman RN, Roy U (2017) Designing configuration of shell-and-tube heat exchangers using grey wolf optimisation technique. Int J Autom Control 11:274. https://doi.org/10.1504/ IJAAC.2017.10004063

53. Zitzler E, Deb K, Thiele L (2000) Comparison of multiobjective evolutionary algorithms: empirical results. Evol Comput 8:173195. https://doi.org/10.1162/106365600568202

54. Schott JR (1995) Fault-tolerant design using single and multicriteria genetic algorithm optimization, Dissertation, Massachusetts Institute of Technology (USA)

55. Rao RV, Rai DP, Balic J (2017) Multi-objective optimization of abrasive waterjet machining process using Jaya algorithm and PROMETHEE method. J Intell Manuf. https://doi.org/10.1007/ s10845-017-1373-8

56. Hwang C-L, Yoon K (1981) Multiple attribute decision making: methods and applications: a state-of-the-art survey. Springer, Berlin

Publisher's Note Springer Nature remains neutral with regard to jurisdictional claims in published maps and institutional affiliations. 